\title{
REVIEW
}

\section{lodothyronine deiodinases: a functional and evolutionary perspective}

\author{
Aurea Orozco, Carlos Valverde-R, Aurora Olvera and Carlota García-G $\mathbf{1}^{\mathbf{1}}$ \\ Instituto de Neurobiología, Universidad Nacional Autónoma de México (UNAM), Boulevard Juriquilla 3001, Juriquilla, Querétaro 76230, México \\ ${ }^{1}$ Departamento de Investigación Biomédica, Facultad de Medicina, Universidad Autónoma de Querétaro, Clavel 200, Querétaro 76017, México \\ (Correspondence should be addressed to A Orozco; Email: aureao@servidor.unam.mx)
}

\begin{abstract}
From an evolutionary perspective, deiodinases may be considered pivotal players in the emergence and functional diversification of both thyroidal systems (TS) and their iodinated messengers. To better understand the evolutionary pathway and the concomitant functional diversification of vertebrate deiodinases, in the present review we summarized the highlights of the available information regarding this ubiquitous enzymatic component that represents the final, common physiological link of TS. The information reviewed here suggests that deiodination of tyrosine metabolites is an ancient feature of all chordates studied to date and
\end{abstract}

consequently, that it precedes the integration of the TS that characterize vertebrates. Phylogenetic analysis presented here points to D1 as the oldest vertebrate deiodinase and to D2 as the most recent deiodinase gene, a hypothesis that agrees with the notion that D2 is the most specialized and finely regulated member of the family and plays a key role in vertebrate neurogenesis. Thus, deiodinases seem to be major participants in the evolution and functional expansion of the complex regulatory network of TS found in vertebrates.

Journal of Endocrinology (2012) 215, 207-219

\section{Introduction}

Thyroidal systems (TS) occur exclusively in vertebrates and seem to have evolved by the selection and functional diversification of iodine, the scarcest and heaviest natural halogen known to be essential for living systems. In vertebrates, iodine is critical for the synthesis of iodothyronines or thyroid hormones (THs), which, according to the ontogenetic stage of the organism, regulate early and postembryonic developmental processes and metabolic balance (Eales 1997, Valverde-R et al. 2004, Yun et al. 2005, Tata 2006). The major $\mathrm{TH}$ in circulation is thyroxine $\left(\mathrm{T}_{4}\right)$ whose synthesis is restricted to the thyroid gland. The main physiological role of $\mathrm{T}_{4}$ is to serve as a pro-hormone that, through its organ-specific dehalogenation, can be tailored into a family of active or inactive iodinated compounds. Hence, orchestrated by the network of neuroendocrine signals that assemble the classic hypothalamic-pituitarythyroid axis (HPT), true TS comprise a fourth target-cell enzymatic component. This important physiological feature of TS, in which the action of its iodine-containing chemical messengers is finely tuned at the local target-cell level, is subserved by a set of ubiquitous reductive dehalogenases generally named iodothyronine deiodinases (Ds). Indeed, iodothyronine deiodination is the essential first step in the pre-receptor control mechanism of $\mathrm{TH}$ action (Nobel et al. 2001). From an evolutionary perspective, Ds may be considered pivotal players in the emergence and functional diversification of both TS and their iodinated messengers. To better understand the evolutionary pathway and the concomitant functional diversification of Ds, in the present review we summarized the highlights of the available information regarding this enzymatic component that represents the final, common physiological link of TS.

\section{Overview of the deiodinase family}

Deiodinases are dimeric integral-membrane, thyroredoxin fold-containing selenoproteins that catalyze the stereospecific and sequential removal of iodine atoms from the pro-hormone $T_{4}$, generating active and inactive isomers of both triiodothyronine $\left(T_{3}\right)$ and diiodothyronine $\left(T_{2}\right)$. This biotransformation of $\mathrm{TH}$ occurs in practically every tissue of the organism and is catalyzed by three distinct deiodinase isotypes: D1, D2, and D3, each with different catalytic properties and specific tissue and developmental expressions. Two deiodinases, D1 and D2, serve the activating or outer ring-deiodinating pathway (ORD) by converting $T_{4}$ to $T_{3}$. The inactivating or inner ring-deiodinating pathway (IRD) is 
catalyzed primarily by $\mathrm{D} 3$, which converts $\mathrm{T}_{4}$ and $\mathrm{T}_{3}$ into inactive metabolites (reverse $\mathrm{T}_{3}\left(\mathrm{rT}_{3}\right)$ and $3,3^{\prime}-\mathrm{T}_{2}$ respectively). Thus, peripheral Ds tightly regulate, in an organ-specific manner, both circulating levels and the local intracellular concentrations of active and inactive $\mathrm{TH}$ (reviewed by Gereben et al. (2008)).

In spite of their distinct functional roles in $\mathrm{TH}$ homeostasis, members of this enzyme family share a common structural organization, thus suggesting that they may have diverged from a common ancestral gene. Although from mammals to fish D1 and D2 are coded by single genes and the majority of vertebrates also have a single gene for D3, most studied fish species have two genes coding for different isoforms of D3 (Valverde-R et al. 2004, Klootwijk et al. 2011). The three deiodinases are dimeric integral-membrane proteins of $\sim 60 \mathrm{kDa}$ anchored to cellular membranes through a single transmembrane (TM) segment within their first 16-40 amino-terminal residues. This membrane segment is partly responsible for the specific subcellular topology that characterizes this enzyme family: D1 and D3 reside at the plasma membrane and D2 at the endoplasmic reticulum, thus allowing the intracellular availability of active and inactive $\mathrm{TH}$ to be precisely regulated based on tissue-specific and functional demand (Fig. 1). Protein modeling of human Ds suggests that the three paralogs belong to the thioredoxinfold protein family and share strong similarities with the active site of iduronidase, a member of the GH-A-fold of glycoside hydrolase family. Their proposed molecular arrangement consists of four functional domains known as: TM, hinge $(\mathrm{H})$, linker (L), and globular or catalytic (G), with the TM and G domains being essential for protein dimerization and hence for its full catalytic activity (Callebaut et al. 2003). Of note is the fact that although its physiological significance remains unknown, there is a low level of heterodimerization between D3:D1 and D3:D2 (Curcio-Morelli et al. 2003, Sagar et al. 2008). In the three deiodinases, the $G$ domain encompasses a highly conserved (77\% identity) 'core' sequence of 49 amino acids (115-163; human D1 numbering) with the selenocysteine (SeCys) residue in positions 126, 133, and 144 in D1, D2, and D3 respectively (Fig. 2). This 'core' sequence includes a segment, which we will refer to as the 'signature string', that consists of nine highly conserved residues: $\mathrm{FGS}(\mathrm{C} / \mathrm{A})(\mathrm{T} / \mathrm{S}) \mathrm{XP}(\mathrm{P} / \mathrm{S}) \mathrm{F}$. Also in all Ds, the 'core' sequence includes a second, well-conserved group of 16 residues (148-163, D1 numbering), which has been implicated in the homodimerization of the protein and is known as the deiodinase dimerization domain (DDD). Of these 16, the key residues are (I/V)Y(I/L/V) (152-154) for D1, two subdomains F(L/V)LYI (153-157) and SDG (164-166) for D2, and (I/V)YI (170-172) for D3 (Leonard et al. 2005, Sagar et al. 2008). In this context, a notable feature of all members of the deiodinase family is that when aligned (Fig. 2), they can be divided into two distinct regions: a conserved region (CR) that comprises the G and DDD domains (115-249, human

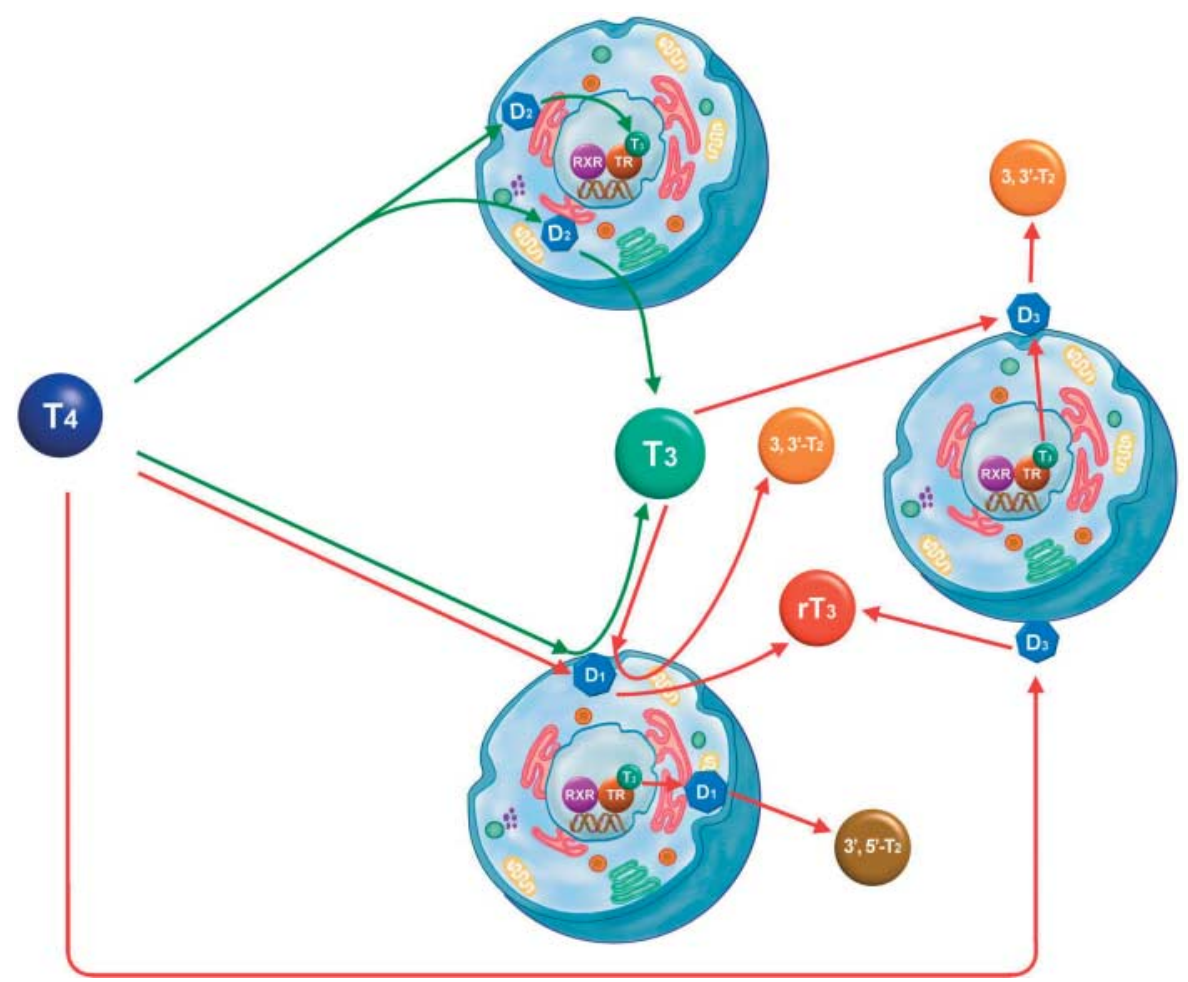

Figure 1 Subcellular topology and function of deiodinases. Green and red arrows show the activating and inactivating pathway respectively. 


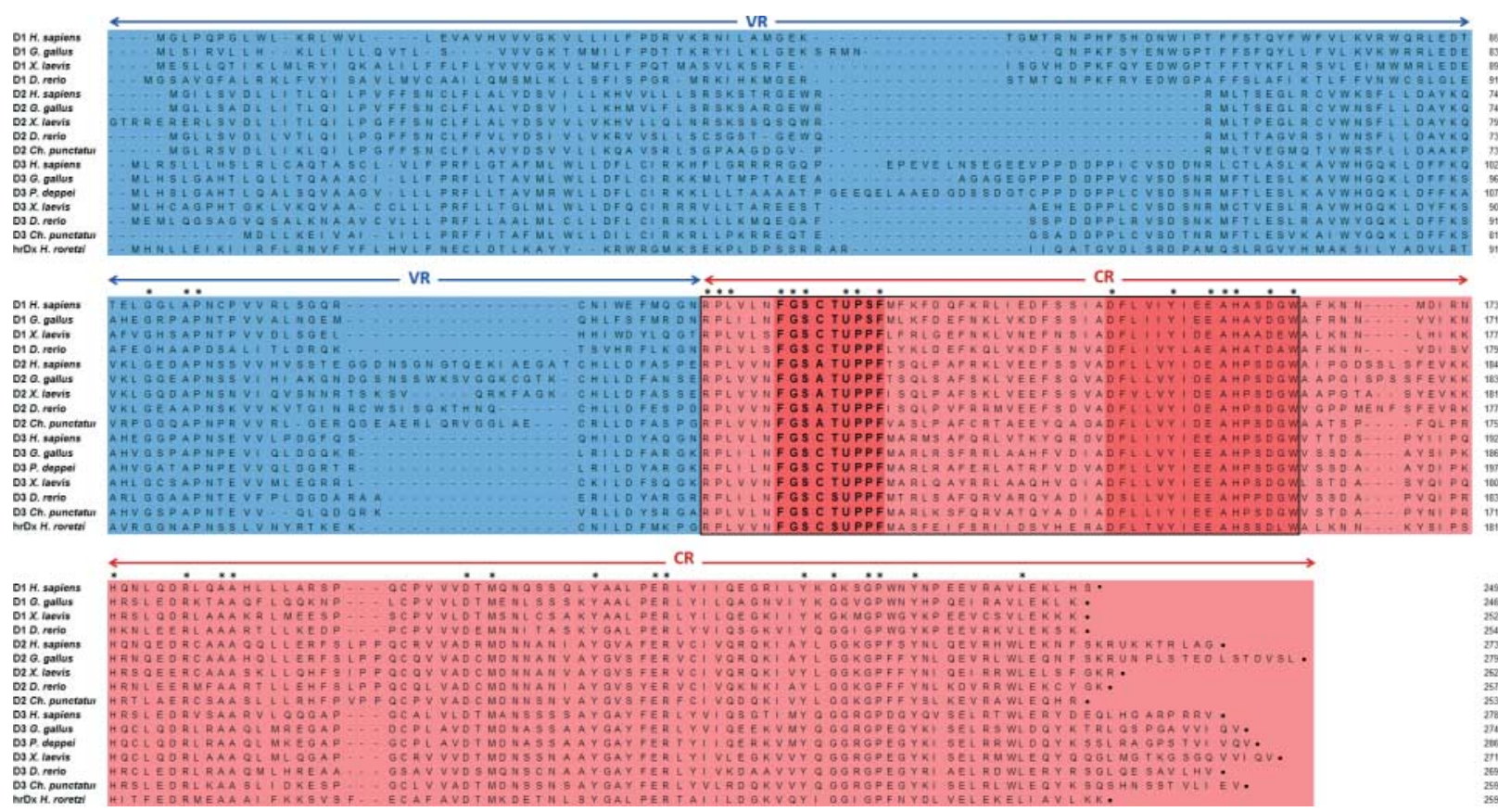

Figure 2 Sequence alignment of the three deiodinases in representative species. The arrows indicate the limits of the VR and CR in blue and red respectively. The 'core' sequence of 49 amino acids is contained in the box. In the VR, only three amino acids are well conserved between species, while the CR contains 31 conserved amino acids among species including the ascidian Halocynthia roretzi. The 'signature string' and a second well-conserved group are shaded dark red. The invariant amino acids are indicated with an asterisk. Black dots represent the $\mathrm{COOH}$ termini. Sequence information used for analysis: D1: Bos taurus gi, 169791016; Chrysiptera cyanea gi, 291170272; Canis lupus familiaris gi, 14717808; Danio rerio gi, 148277097; Equus caballus gi, 262050548; Felis catus gi, 57163803; Fundulus heteroclitus gi, 28144872; Gallus gallus gi, 148277086; Homo sapiens gi, 13195755; Macaca mulatta gi, 169790989; Mus musculus gi, 110825976; Oryctolagus cuniculus gi, 153791214; Paralichthys olivaceus gi, 171451963; Pan troglodytes gi, 169790987; Rattus norvegicus gi, 51988898; Sparus aurata gi, 116734190; Suncus murinus gi, 15128559; Sus scrofa gi, 48675925; Takifugu rubripes gi, 169659160; Xenopus laevis gi, 71841595. D2: Bos taurus gi, 58330899; Chrysiptera cyanea gi, 291170270; Coturnix japonica gi, 171948719; Canis lupus familiaris gi, 169790961; Danio rerio gi, 52630451; Equus caballus gi, 262050558; Fundulus heteroclitus gi, 14717797; Gallus gallus gi, 4927718; Homo sapiens gi, 1518542; Mus musculus gi, 6753638; Neoceratodus forsteri gi, 22128042; Oryctolagus cuniculus gi, 126572617; Oryzias latipes gi, 211904101; Oncorhynchus mykiss gi, 16550970; Paralichthys olivaceus gi, 71451965; Rana catesbeiana gi, 14717792; Rattus norvegicus gi, 132566529; Siganus guttatus gi, 283858738; Sus scrofa gi, 48675915; Takifugu rubripes gi, 169659162; Xenopus laevis gi, 13811437. D3: Bos taurus gi, 58330894; Carassius auratus gi, 145336998;

Chrysiptera cyanea gi, 291170274; Chiloscyllium punctatum gi, 161328016; Danio rerio gi, 295789007; Gallus gallus gi, 169790979; Homo sapiens gi, 56103188; Macaca mulatta gi, 169790981; Mus musculus gi, 76827841; Neoceratodus forsteri gi, 37912833; Ovis aries gi, 169790985; Oreochromis niloticus gi, 5824106; Pituophis deppei gi, 270056392; Paralichthys olivaceus gi, 171451967; Rana catesbeiana gi, 14717804; Sparus aurata gi, 116734194; Sus scrofa gi, 48675921; Takifugu rubripes gi, 169659164; Xenopus laevis gi, 14717810; and Xenopus tropicalis gi, 169791009. Outgroup: Halocynthia roretzi gi, 38640513.

D1 numbering) and a variable region (VR) that includes the remaining three domains. As discussed later, the analysis of these two regions may provide important clues regarding the evolutionary path of this enzyme family. Of note is the fact that as we found minor discrepancies in the sequence data between different data bases, for the present review we only considered sequence information from GenBank.

All Ds contain at their active center ( $G$ domain) the modified amino acid SeCys, which is encoded by an in-frame UGA triplet that functions as a codon for the incorporation of the rare amino acid (Berry et al. 1991). At physiological $\mathrm{pH}, \mathrm{SeCys}$ is ionized and becomes a potent electron donor, which favors an efficient deiodinating reaction (reviewed in Gereben et al. (2008)). Also, all Ds contain in their $3^{\prime}$ UTRs a selenocysteine insertion sequence (SECIS), which is a cis-acting signal required for the incorporation of SeCys into the protein during translation. SECIS elements form non-Watson-Crick base pairs and have been found to adopt two alternative hairpin loops, designated form 1 or form 2 (reviewed in Bianco et al. (2002)). The functional implications of this variation are unknown, as there is no clear evidence that the two forms of the SECIS element differ in their effects upon mRNA translation in other selenoproteins (Fagegaltier et al. 2000). Furthermore, deiodinase transcription requires an ancient and very complex trans-acting machinery; the mechanisms involved in this process were recently reviewed ( $\mathrm{Lu} \&$ Holmgren 2009, Palioura et al. 2009). 


\section{Deiodinase genes}

Owing to the availability of whole-genome sequencing, Ds genes (DIO1, DIO2, and DIO3) have been identified in a number of vertebrate species including mammals, birds, amphibians, and fish; however, no genomic information on reptilian Ds is yet available. All DIO1 genes described thus far comprise four to five exons from which one (chimpanzee, rat, and chicken), two (zebrafish), five (macaque), eight (mouse), or 14 (human) transcripts can be generated. The location of Dio 1 varies greatly among species; however, it is contained on chromosome 1 in all primate genomes analyzed. The beststudied promoter region of a Dio1 is that of human, which contains two thyroid hormone responsive elements (TREs, Toyoda et al. 1995). Dio2 and Dio3 are co-localized on the same chromosome in most of the species with available sequenced genomes, i.e. human, macaque, chimpanzee, rat, mouse, dog, horse, pig, and chicken (chromosome 14, 7, 14, $6,12,8,24,7$, and 5 respectively). The structure of Dio 2 comprises two exons spliced by a single intron. The size of the intron varies among species, the teleostean intron being the smallest $(4.7 \mathrm{~kb})$; however, all are located at the same position within the mRNA transcript. There is only one transcript from Dio2, with the exception of human and chimpanzee in which 12 and two transcripts of the gene have been found respectively. The physiological importance of these different forms of mRNA is still unknown. The promoter region of Dio2 has been analyzed in only a few species. Some differences that could be of phylogenetic relevance may explain its differential expression observed in various vertebrate species. In contrast to the mammalian Dio2, no TATA or CCAAT boxes were found in the teleostean homolog (Orozco et al. 2002). Furthermore, the human, rat, and mouse genes contain a single, completely conserved canonical cAMP response element (CRE) around $70 \mathrm{bp}$ upstream of the TATA box, but no CRE sequence is present within $1.3 \mathrm{~kb}$ upstream of the killifish gene. Additionally, only the human DIO2 is stimulated by thyroid transcription factor 1 (TTF1; Gereben et al. 2001). Unlike Dio1 and Dio2, no introns are present in the Dio 3 genes analyzed thus far (human, macaque, chimpanzee, rat, mouse, chicken, and zebrafish). Thus, Dio3 has been included among the rare genes in the eukaryotic kingdom (6\% of total genome) that have no introns (Hernandez et al. 1999). Mouse Dio3 is imprinted and preferentially expressed from the paternal allele (Hernandez et al. 2002).

\section{Deiodinase mRNAs}

The number of identified deiodinase mRNAs has greatly increased in the last few years. In the present review, we have included only the available full-length (open reading frame) sequences that have been characterized biochemically and/or molecularly. Among these sequences, D1, D2, and D3 are highly conserved as judged by the 68,75 , and $69 \%$ identity, respectively, at the amino acid level. At variance with the other deiodinases, D3 mRNAs have been identified in all five classes of vertebrates including chondrichthyans and reptiles, and snake D3 is the longest so far reported (Martínez et al. 2008, Villalobos et al. 2010). All known deiodinase mRNAs include a SeCys-encoding TGA codon as well as a SECIS element in the $3^{\prime}$-UTR. SECIS elements have been found to adopt two alternative hairpin loops, designated form 1 or form 2. In form 1 structures, the essential AA(A) nucleotides are contained in a single open loop. By contrast, in form 2 the adenosines are located in a second bulged region. The predicted secondary structure of the D1 SECIS resembles that of form 1, with the single exception of the killifish, which resembles form 2 (Orozco et al. 2003). In all D2 and D3 mRNAs, the predicted secondary structure closely resembles that of SECIS form 2. A unique feature of D2 mRNAs is the presence of a second, in-frame TGA codon that located four to eight amino acids from the $\mathrm{C}$-terminus of the protein; however, this site is not critical for deiodination (St Germain \& Galton 1997, Orozco et al. 2002).

\section{Deiodinase protein}

\section{Subcellular topology}

Deiodinases are differentially localized at the subcellular level. D1 is a plasma membrane protein with its catalytic globular domain facing the cytosol, whereas the TM domain of D2 is anchored to the endoplasmic reticulum and its globular domain, including the active site, faces the perinuclear cytosol. D3 is anchored in the plasma membrane, with most of the molecule, including the active center, facing the extracellular space. D3 undergoes an unusual bidirectional recycling between plasma membrane and early endosomes. Indeed, recent studies have shown that plasma membrane D3 recycles rapidly to the early endosomal compartment, and apparently only a minute fraction progresses to late endosomes and to lysosomal proteolysis. The rest of the endosomal D3 pool is potentially recyclable, which could constitute a mechanism to reexpose the selenium-containing active center of the enzyme at the cell surface. Retention of internalized D3 in early endosomes could explain its long half-life $(\sim 12 \mathrm{~h})$ and allows for the possibility that an appropriate signal could lead to its rapid relocalization to the cell surface with a consequent acute inactivation of circulating $\mathrm{T}_{4}$ and $\mathrm{T}_{3}$ (Fig. 1; reviewed in Gereben et al. (2008)).

\section{Biochemical properties}

The pattern of deiodinase expression varies somewhat between species (Table 1). Although initially elusive in amphibians, D1 orthologs have been found recently in the genomes of Xenopus laevis and Xenopus tropicalis (Kuiper et al. 2006). The difficulty in identifying amphibian D1 activity 


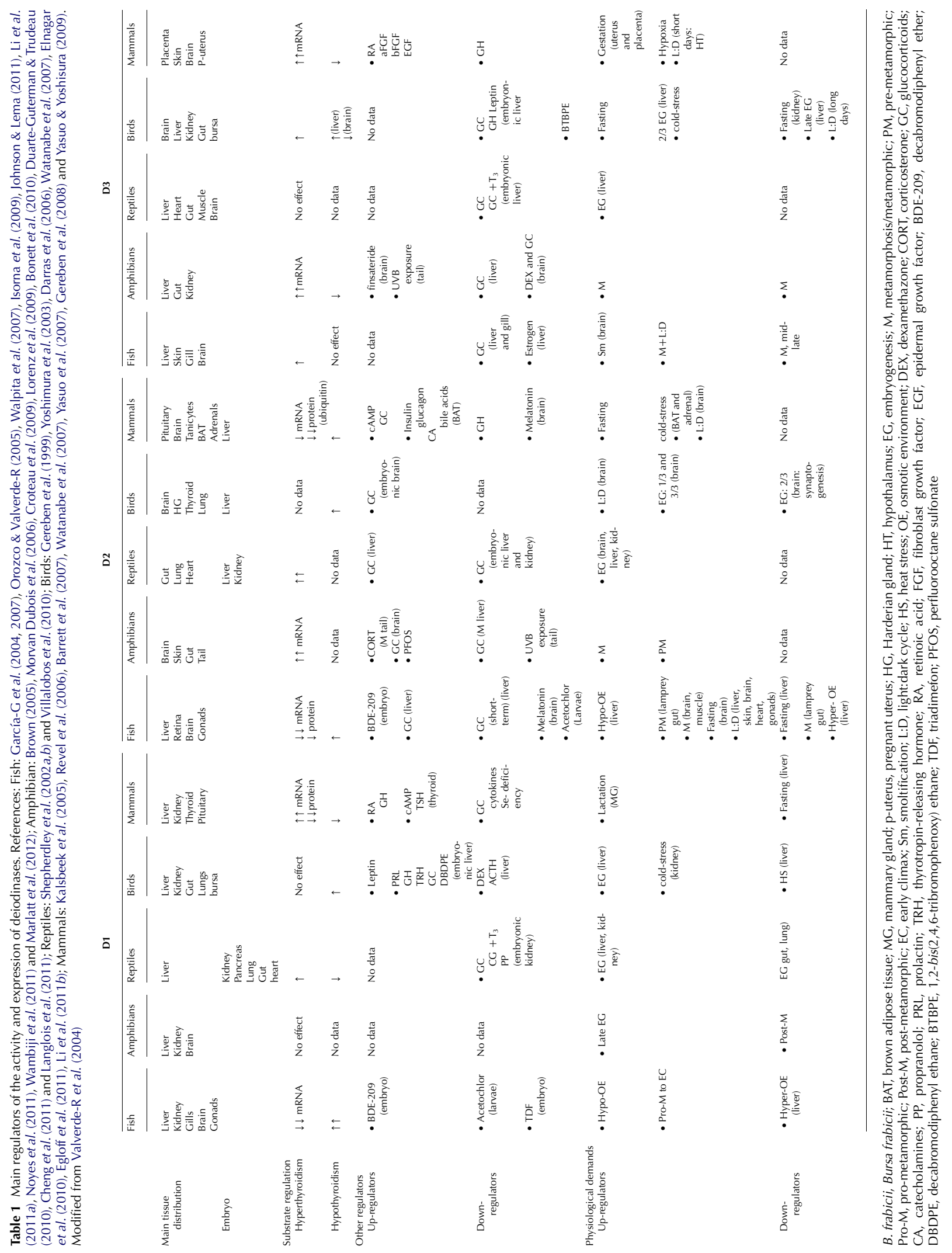


resulted from the biochemical properties of the enzyme. Indeed, a critically important characteristic of D1-catalyzed deiodination is its remarkable sensitivity to inhibition by 6-n-propyl-2-thiouracil (PTU), with the exception of fish (Orozco et al. 1997, 2000, Sanders et al. 1997) and amphibian D1 (Kuiper et al. 2006), which are less sensitive to this inhibitor. In fact, PTU sensitivity has been used to demonstrate the specificity of $T_{4}$ to $T_{3}$ conversion and to distinguish D1 from the other Ds. The amino acids in the active center of D1 are highly conserved in various species (Fig. 2). The only known exceptions are fish and frog, in which proline replaces serine at position 128 and 132 respectively (Sanders et al. 1997, Orozco et al. 2003, Kuiper et al. 2006). Of note is the fact that the D 2 and D 3 enzymes, which are PTU-insensitive, also contain the proline residue at the corresponding position. Interestingly, site-directed mutagenesis has shown that the proline/serine change can explain frog (Kuiper et al. 2006), but not fish, D1 PTU insensitivity (Sanders et al. 1997, Orozco et al. 2003). This differential response to PTU between mammalian D1 and the amphibian and teleostean orthologs probably reflects a difference in the function of the enzyme in these species. In mammals and chicken, D1 is usually highly expressed in the liver, which plays an important role in regulating plasma $T_{3}$ levels (reviewed in Darras et al. (2006) and Gereben et al. (2008)). By contrast, D1 function in teleostean and amphibian $T_{3}$ plasma regulation is less clear (Finnson et al. 1999, Kuiper et al. 2006). Another indication for a different function might be that sulfated iodothyronines $\left(\mathrm{rT}_{3} \mathrm{~S}, \mathrm{~T}_{3} \mathrm{~S}\right.$, and $\left.\mathrm{T}_{4} \mathrm{~S}\right)$ are very good substrates for mammalian D1 enzymes, but not for the teleostean or amphibian orthologs (Sanders et al. 1997, Finnson et al. 1999).

Aside from the peculiar PTU insensitivity, some, but not all, teleostean D1s exhibit yet another distinct feature related to their use of cofactors in the deiodinase reaction. The catalytic cycle of all Ds depends on a reducing thiol co-substrate that regenerates the selenoenzyme to its native state. Although no endogenous co-substrate has been identified, dithiothreitol (DTT) is commonly used to activate the enzymes in vitro. Both gilthead seabream kidney (Klaren et al. 2005) and killifish gill (Orozco et al. 2000) D1s have been shown to be inhibited by DTT. This kinetic characteristic seems be tissue specific.

\section{The physiological role of deiodinases}

D1 is the only member of the family that catalyzes both ORD and IRD of various iodothyronine derivatives. This complex dual catalytic activity suggests that D1 could have more than one function. Indeed, besides contributing to the circulating $\mathrm{T}_{3}$ pool, the enzyme recycles iodine and operates as a scavenger, clearing plasma $\mathrm{rT}_{3}$ and other inactive sulfated iodometabolites (Fig. 1; Schneider et al. 2006, Gereben et al. 2008). Models of deiodinase deficiency have helped to understand the physiological role of Ds. In this context, D1 knockout (KO) alone (Schneider et al. 2006) and combined D1/D2-KO (Galton et al. 2009) have shown that D1 may also play an important role in limiting the detrimental effects of conditions that alter normal thyroid function, like hyperthyroidism and iodine deficiency. This notion could apply to other vertebrates, as zebrafish D1 knockdown is only detrimental (developmental delay and dysmorphologies) when combined with a D2 knockdown, suggesting that D1 is only crucial in a depleted thyroidal status (Walpita et al. 2010). Thus, the D1 contribution to the circulating $T_{3}$ pool could be important during specific stages of high demand for $\mathrm{TH}$ such as embryogenesis and metamorphosis of fish and amphibian, as demonstrated by its upregulation during these processes in several species (i.e. Shepherdley et al. (2002b), Morvan Dubois et al. (2006), Campinho et al. (2010) and Itoh et al. (2010)).

D2 is an obligate ORD selenodeiodinase, which mainly catalyzes the conversion of $\mathrm{T}_{4}$ to $\mathrm{T}_{3}$ and $\mathrm{T}_{3}$ to $3,5-\mathrm{T}_{2}$ (Fig. 1). The enzyme is considered to be the critical homeostatic $\mathrm{T}_{3}$-generating deiodinase due to its substantial physiological plasticity. A number of transcriptional and posttranscriptional mechanisms have evolved to ensure limited expression and tight control of the D2 protein level, which is critical for its homeostatic function (see below). D2 is expressed in the mammalian brain, especially in glial cells; astrocytes and the ependymoglial cells known as tanycytes that line the walls and floor of the third ventricle are particularly important in functional terms as they produce more than $75 \%$ of the nuclear $\mathrm{T}_{3}$ in the rat cerebral cortex (Guadaño-Ferraz et al. 1997, Rodríguez et al. 2010, Moháacsik et al. 2011). Another conspicuous functional distinction between D1/D3 and D2 is the fact that the latter exhibits a remarkable circadian rhythm entrained by the light/dark cycle. This rhythmicity has been documented in teleosts (García-G et al. 2004, Isorna et al. 2009), birds (Yoshimura et al. 2003), and mammals (Luna et al. 1995, reviewed in Gereben et al. (2008)) in several neuroendocrine structures, such as the hypothalamus, pituitary, pineal, and adrenal glands, as well as in brown adipose tissue, liver, Harderian gland, and cerebral cortex. Furthermore, recent studies support the notion that D2 expression in hypothalamic tanycytes is an important factor in regulation of seasonal reproduction both in mammals and birds (Williams \& Duncan Bassett 2011, Ikegami \& Yoshimura 2012). Surprisingly, the D2-KO mouse exhibited a very mild phenotype, showing an unimpaired reproductive capacity, small and transient growth abnormalities, and no loss in mobility. The most conspicuous features observed in this $\mathrm{KO}$ model were increased $\mathrm{T}_{4}$ and TSH serum levels, accompanied by a resistance of pituitary TSH to $\mathrm{T}_{4}$. Hence, $\mathrm{D} 2$ seems to be critical in the pituitary/thyroid feedback regulation of TSH secretion, at least in mammals (Schneider et al. 2001). Furthermore, D2-KOs exhibit retarded postnatal development of the cochlea, which resulted in severely impaired auditory function in the adult ( $\mathrm{Ng}$ et al. 2004). Possible defects in other crucial TH-dependent neurodevelopmental functions, such as vision, learning, and memory, are currently unknown. 
D3 has exclusively IRD activity and catalyzes the conversion of $T_{4}$ to $\mathrm{rT}_{3}$ and $\mathrm{T}_{3}$ to $3,3^{\prime}-\mathrm{T}_{2}$, both of which are biologically inactive (Fig. 1). D3 is the predominant deiodinase expressed during embryonic life, and its activity is much higher than that found in adult tissues. Consequently, the enzyme is thought to control $\mathrm{TH}$ homeostasis by protecting tissues from an excess of $\mathrm{TH}$ during the speciesspecific ontogenetic programs. Indeed, although hepatic D3 expression is limited to embryonic life in most vertebrates, during adulthood the enzyme is also expressed in the liver of those omnivorous species that devour whole pray. This finding, which is in accord with the protective role of D3 during embryogenesis, has led to the proposal that hepatic D3 helps to prevent an inappropriate systemic overload of exogenous $\mathrm{T}_{3}$ after feeding (Martínez et al. 2008, Villalobos et al. 2010). In the context of the protective role of D3, it is interesting that expression of this enzyme resumes during critical illness and different hypoxic-ischemic conditions such as myocardial infarction and chronic inflammation (reviewed in Huang \& Bianco (2008), Mebis \& Van den Berghe (2009), Warner \& Beckett (2010) and Solís-S et al. (2011)). Developmental programing of the thyroid axis is markedly perturbed in D3-deficient mice, resulting in a persistent congenital hypothyroidism and causing partial neonatal lethality, growth retardation, and impaired fertility in D3-KOs (Hernandez et al. 2006, St Germain et al. 2009).

\section{Regulation of deiodinases}

As summarized in Table 1, depending on the organ and the species, different hormonal, nutritional, and developmental signals, as well as physiological demands, modulate the expression and activity of Ds. However, TH availability is the most potent and well-studied regulator. In most vertebrates, hyperthyroidism increases D1 activity and transcription, whereas hypothyroidism exerts the opposite effects. In humans, but not in rodents, the presence of two canonical TREs in the $5^{\prime}$ flanking region of DIO1 explains the observed responses to substrate. However, fish D1 exhibits a distinct down-regulatory response. In fish, long- and shortterm $\mathrm{T}_{4}-$ or $\mathrm{T}_{3}$-hyperthyroidism does not alter hepatic D1 activity, but D1 mRNA levels do decrease. Furthermore, long-term hypothyroidism acutely increases hepatic D1 activity and levels of mRNA (reviewed in Orozco \& Valverde-R (2005)).

Hyperthyroidism suppresses D2 activity and the expression of its mRNA in most studied tissues and species, whereas hypothyroidism increases them. Thus, at least in mammals, the very short half-life $(<1 \mathrm{~h})$ of D2 is further shortened in cells exposed to physiological concentrations of its substrate, $\mathrm{T}_{4}$, and in experimental situations, to $\mathrm{rT}_{3}$ or even $\mathrm{T}_{3}$. This down-regulation of D2 activity by substrate is a rapid and potent regulatory feedback loop that efficiently controls $T_{3}$ production and intracellular $T_{3}$ concentration based on the availability of $\mathrm{T}_{4}$. In this regard, experimental data suggest that

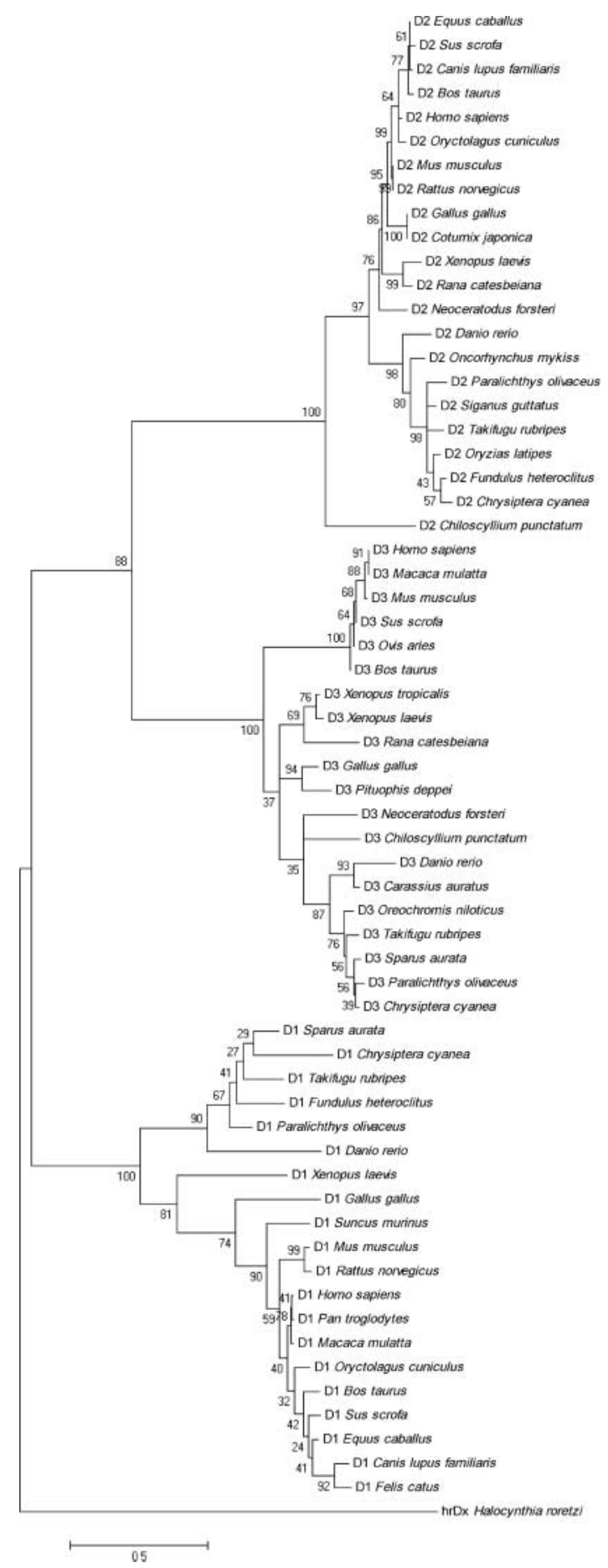

Figure 3 Phylogenetic reconstruction of vertebrate deiodinases. The outgroup represented by hrDx is the basal branch of the tree. Ds are grouped into three clusters, the D1 cluster being the most variable, suggesting that this paralog is the oldest. D2 and D3 clusters are close to each other and exhibit less variability than the D1 cluster; its appearance is more recent. The evolutionary distance scale is the number of amino acid substitutions per site, and the number of nodes represents the bootstrap statistic. 
enzyme-substrate interaction induces selective degradation of the complex in the proteasome, which is initiated by conjugation to ubiquitin. Interestingly, the ubiquitinated D2 can then be either degraded in the proteasome complex or deubiquitinated to its unconjugated form, which reactivates the enzyme. These complex posttranscriptional mechanisms have been extensively studied and reviewed elsewhere (Gereben et al. 2008). By contrast, the molecular mechanisms that explain the pre-transcriptional regulation of D2 by substrate are not yet understood in any vertebrate species. In this context, the presence of a negative TRE in the human DIO2 $5^{\prime}$-FR has been inferred, although it has not yet been identified (Gereben et al. 2008).

It has been reported that in teleost liver, $3,5-\mathrm{T}_{2}$ regulates the activity and expression of D2 (García-G et al. 2004, 2007). Little is known about the kinetics of $3,5-\mathrm{T}_{2}$ in vertebrates; nevertheless, the fact that this iodothyronine clearly regulates D2 suggests that it could play a physiological role in teleostean TS.

As previously mentioned, changes in the activity of D3 modulate both circulating and tissue thyroidal status by accelerating or retarding $\mathrm{T}_{3}$ inactivation to maintain homeostasis. In agreement, thyroidal status parallels D3 activity in several species, increasing during hyperthyroidism and decreasing during hypothyroidism in the CNS (reviewed in Gereben et al. (2008)). This pattern has also been observed in other physiological situations such as in amphibian development, in which the pre-metamorphic surge of $\mathrm{T}_{3}$ rapidly stimulates D3 in frog tadpoles (reviewed in Brown (2005)). The mechanisms of this regulation are still far from clear. Although a dramatic increase of D3 mRNA was observed after short-term (8 days) $\mathrm{T}_{3}$ treatment, it is still not known whether this is a consequence of gene transcription, mRNA stabilization, or a combination of the two factors. Furthermore, the promoter analysis conducted in the rat and human Dio3 showed a positive but modest regulation by $\mathrm{T}_{3}$ (Gereben et al. 2008).

It is important to note that lately, an important effort has been made to analyze the impact that anthropogenic endocrine disruptors have upon deiodinase activity. In fact, D mRNA levels, at least in fish and amphibians, are sensitive to thyroid-disrupting chemicals and may provide useful molecular markers for exposure to them (i.e. Picard-Aitken et al. (2007), Croteau et al. (2009), and Li et al. (2009, 2011a)). Examples of the regulatory effects of some thyroid disruptors on deiodinase expression are also included in Table 1.

\section{Phylogeny of deiodinases}

The synthesis and metabolism of iodine-containing informational molecules, particularly the iodinated tyrosine messengers that characterize vertebrate TS, seem to have originated at the base of deuterostomes and evolved for endocrine function by the exploitation and diversification

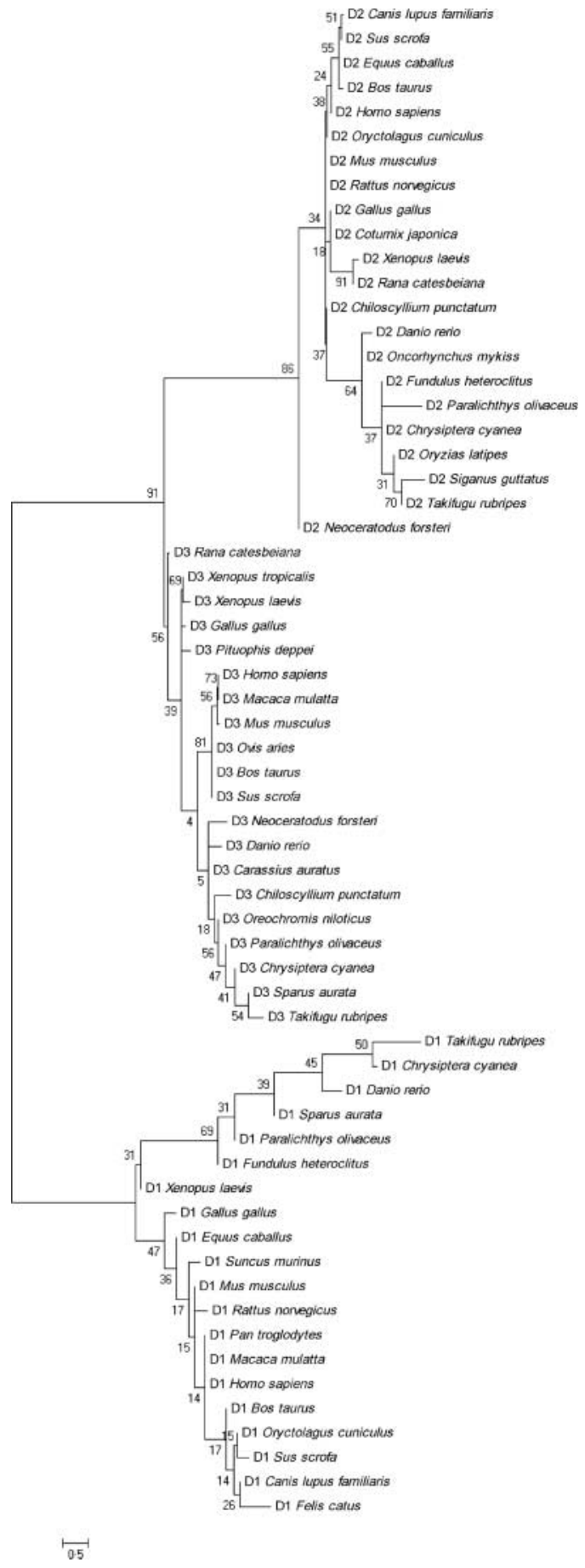

Figure 4 Phylogenetic reconstruction of VR vertebrate deiodinases. The topology of the tree shows similarity with the tree of complete sequences. Among the three paralogs, the largest variability (length of branches) corresponds to D1, particularly in fish and amphibian orthologs. The VR shows more amino acid replacements over time (compare with Fig. 5), suggesting that this region is the target of evolutionary innovation. The evolutionary distance scale is the number of amino acid substitutions per site, and the number of nodes represents the bootstrap statistic. 
of the complementary enzymatic dyad of halogenation/ dehalogenation (for review Eales (1997) and Valverde-R et al. (2004)). Indeed, current information supports the notion that the vertebrate thyroid gland, as well as the endostyle and subpharyngeal gland in invertebrate chordates, may have evolved from a common ancestor (for review Kluge et al. (2005) and Paris et al. (2008)). Thus, the genomes of cephalochordates (amphioxus) and urochordates (tunicates) contain orthologs of the main genes involved in thyroid hormonogenesis and the TH-signaling pathway $(\mathrm{Na} / \mathrm{I}$ symporter, thyroid peroxidase, deiodinase, and $\mathrm{TH}$ receptor), but they lack the components for neuroendocrine control of the thyroid (for review: Holland et al. (2008) and Paris et al. (2008)). In the ascidian Halocynthia roretzy, at least one deiodinase homolog $(\mathrm{hrDx})$ has been biochemically characterized. The enzyme presents a bona fide SECIS and conserves the signature string that characterizes vertebrate deiodinases. The catalytic activity of $\mathrm{hrDx}$ resembles a vertebrate D1 enzyme as it shows ORD activity, ping-pong kinetics, and prefers $\mathrm{rT}_{3}$ as substrate. However like fish and amphibian D1s, hrDx is PTU-insensitive and contains proline instead of serine at the corresponding site (see Section Deiodinase protein; Shepherdley et al. 2004). In the amphioxus, Branchiostoma floridae, three deiodinase homologs have recently been cloned: at their catalytic site, two have SeCys. The only one that has been characterized, bfDy, has a Cys residue; does not deiodinate $\mathrm{T}_{4}, \mathrm{~T}_{3}$, or $\mathrm{rT}_{3}$; is not inhibited by PTU; and specifically catalyzes the IRD of thyroacetic acid metabolites of $\mathrm{T}_{4}$ and $\mathrm{T}_{3}$ (TA4 and TA3 respectively; Klootwijk et al. 2011). Furthermore, these acidic metabolites are the endogenous ligands of $B$. floridae $\mathrm{TH}$ receptors and they control metamorphosis in this species, supporting the notion that even in invertebrate chordates, this distinct, inactivating deiodinative pathway is physiologically relevant (Paris et al. 2008, 2010). Interestingly, these invertebrate chordate deiodinase homologs could have an even more ancient origin, and there is evidence that invertebrates like the scallop (Chlamys farreri; Wu et al. 2012) and the echinoderm (Strongylocentrotus purpuratus; Heyland et al. 2006) may express putative deiodinases. Thus, deiodinase functional diversity in extant vertebrates seems to stem from a common ancestral molecular scaffold that could have already been present in the ancient metazoa. Even though there is no information regarding the catalytic activities of the remaining two SeCys-containing, putative B. floridae homologs, the singular substrate selectivity of bfDy poses the intriguing question of whether ancestral deiodinases played a protective role, as does the extant vertebrate IRD, and/or fulfilled multiple roles that were later divided among several enzymes.

With the aim to trace the evolutionary history of Ds, we compared and analyzed (neighbor-joining) available D1, D2, and D3 peptide sequences retrieved from 33 species ranging from chondrichthyan and teleost fishes to mammals, as well as the urochordate $\mathrm{hrDx}$, all of which have been expressed and/or characterized in functional terms. As depicted in Fig. 2 and advanced in the 'Deiodinase overview' section, the

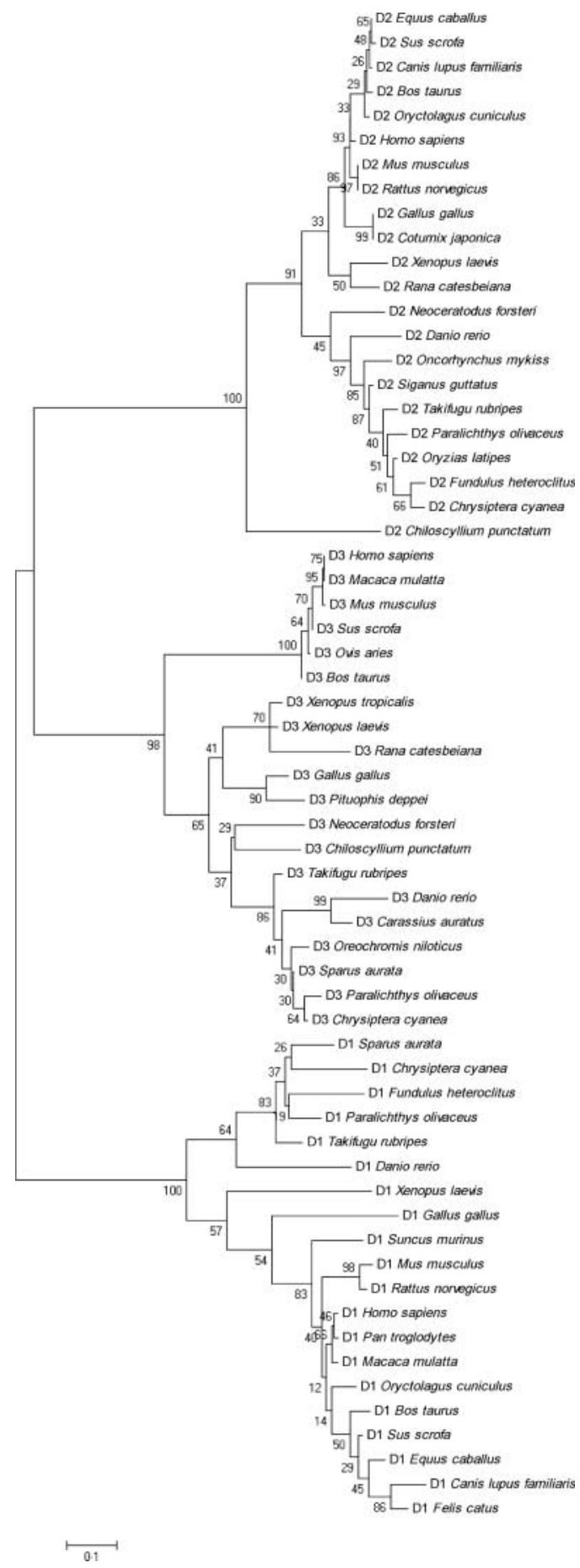

Figure 5 Phylogenetic reconstruction of CR vertebrate deiodinases. The topology of the tree shows that this region exhibits an important degree of conservation, which is more evident in the case of mammalian D2. This homogeneity shows that this region has been under a tight selective pressure maintaining its structure highly conserved among species. The evolutionary distance scale is the number of amino acid substitutions per site, and the number of nodes represents the bootstrap statistic. 
initial alignment of the three vertebrate deiodinases (20 D1, 22 D2, and 20 D3 sequences) revealed a 45\% identity among paralogs and 68, 75, and 69\% among orthologs respectively. We then separately analyzed the protein sequences of Ds in two major regions: the first half or 'VR' includes the TM, H, and L domains, while the second half corresponds to the 'CR' and contains the $\mathrm{G}$ domain. Our results revealed that although the $\mathrm{G}$ domains are very similar (60\% identity), the remaining domains (TM, H, and L) are the most variable (20\% identity) among paralogs but, interestingly, are relatively conserved domains among orthologs (D1, 50\%; D2, 55\%; and D3, $60 \%$ identity). In hrDx, only the $\mathrm{G}$ domain is highly conserved, and it contains the nine amino acid signature string $\mathrm{FGS}(\mathrm{C} / \mathrm{A})(\mathrm{T} / \mathrm{S}) \mathrm{XP}(\mathrm{P} / \mathrm{S}) \mathrm{F}$ (Fig. 2).

As expected and depicted in Fig. 2, the phylogenetic analysis resolves the different orthologs into three distinct clusters whose branches represent the evolutionary distance between deiodinase paralogs within the vertebrate phyla. For this analysis, we used hrDx as the out-group, in contrast to bfDy, as it is a SeCys-containing deiodinase. As observed (Fig. 3), hrDx is resolved at the base of the tree placing it as the most ancient. Between vertebrate deiodinases, the D1 cluster appears before that of D2 and D3, and it exhibits longer branches, which represent a high rate of evolutionary change; thus, this analysis suggests that it is the oldest of the three deiodinases. D2 and D3 share a node that represents an immediate common ancestor that could have resembled D1 in that it contained both activating and inactivating activities; by duplication, the two resulting genes acquired specialized functions.

As shown in Fig. 4, the phylogenetic analysis of the VR of the three deiodinase paralogs reveals that this region displays the greatest rate of evolutionary change. Indeed, the evolutionary distance scale is longer than that of the CR phylogenetic tree ( 0.5 vs $0 \cdot 1$ respectively). This suggests that the VR has been under a more relaxed selective pressure with the consequent gain of change and physiologic novelty. Furthermore, due in part to the reduced number and/or the lack of sequences from the three paralogs covering the entire vertebrate phyla, these changes are more evident when comparing fishes and mammals (Fig. 3), the vertebrate classes with the largest number of available D sequences (6-10 and 6-12 respectively). However, note that the amino acid substitutions among orthologs are not random but biochemically equivalent, thus maintaining the hydrophobic clusters in relatively constant same positions in the corresponding VR. This bioequivalence between orthologs could explain their shared features. With these caveats in mind, it is nevertheless important to notice that subtle differences among orthologs could be due to environmental and/or physiological species-specific demands.

In D1, variability was also highest in the VR. This, together with the topology of the VR phylogenetic tree, is consistent with our suggestion that D1 is the oldest vertebrate deiodinase. This suggestion is based on the notion that the longer the enzyme exists, the higher the opportunity for variation, expressed as mutations. In this context, the facts that D3 in most studied fish species is encoded by two genes and that Dio 2 and Dio 3 co-localize on the same chromosome suggest that the two enzymes may have evolved by gene duplication. This event is believed to play a major role in evolution because the additional copy would be relatively free from selective pressure, thus providing a source of genetic material for mutation, drift, and selection to act upon, making new evolutionary opportunities possible. In this context, the phylogenetic trees are presented here to point D2 as the most recent deiodinase gene. This hypothesis agrees with the notion that D2 is the most specialized and finely regulated member of the family and plays a key role in vertebrate neurogenesis.

The highly conserved identity of the CR is a consequence of the low rate of evolutionary change, as judged by the homogeneous distances of the phylogenetic tree branches (Fig. 5). Under an evolutionary scenario, it is reasonably valid to assume that the $\mathrm{G}$ domain in deiodinases has been under a tight selective pressure, maintaining a structure that is highly conserved among species. In fact, the $G$ domain seems to be conserved in all enzymes so far identified (Dx, hrDx, and bfDy) that metabolize iodinated tyrosine compounds, supporting the idea that these enzymes are central components of an ancient and preserved homeostatic strategy. This notion is worthy of further attention and represents a frontier of knowledge in thyroid physiology.

\section{Concluding remarks}

In general, the ligand/receptor couple has been considered central for the understanding of the origin and functional diversification of endocrine systems. However, in those systems in which, as in the case of $\mathrm{TH}$, ligand activity depends on its enzymatic biotransformation at the prereceptor level, a third player must be considered to fully understand the evolution and functional expansion of the system. By selectively removing iodine atoms from one or another of the two tyrosine rings of the halogen-containing messenger, deiodinases represent a sophisticated, tissuespecific on/off switch for regulating $\mathrm{TH}$ activity. Indeed, the information reviewed here suggests that deiodination of tyrosine metabolites is an ancient feature of all chordates studied to date and consequently, that it precedes the integration of the TS proper that characterizes vertebrates. In fact, like their vertebrate counterparts, the non-SeCys deiodinase homologs in cephalochordates and urochordates are instrumental in regulating metamorphosis, a transitional stage of development conserved in all chordates and in which $\mathrm{TH}$ and/or some of its iodine derivatives are the key physiological regulators (Paris et al. 2008, 2010, Laudet 2011). Thus, deiodinases seem to be major players in the evolution and functional expansion of the complex regulatory network of TS found in vertebrates. As previously stated, the comparative approach in the study of TS is unavoidable, because, according to Dobzhansky (1973), 'Nothing in biology makes sense, except in the light of evolution'. 


\section{Declaration of interest}

The authors declare that there is no conflict of interest that could be perceived as prejudicing the impartiality of the review reported.

\section{Funding}

This study was supported by grants from PAPIIT 208511 and CONACyT 166357 and 106214. C G receives postdoctoral fellowship, CVU 39615.

\section{Acknowledgements}

The authors acknowledge the technical support of Patricia Villalobos and Leonor Casanova. They thank Dorothy Pless for critically reviewing the manuscript.

\section{References}

Barrett P, Ebling FJ, Schuhler S, Wilson D, Ross AW, Warner A, Jethwa P, Boelen A, Visser TJ, Ozanne DM et al. 2007 Hypothalamic thyroid hormone catabolism acts as a gatekeeper for the seasonal control of body weight and reproduction. Endocrinology 148 3608-3617. (doi:10.1210/ en.2007-0316)

Berry MJ, Banu L \& Larsen PR 1991 Type I iodothyronine deiodinase is a selenocysteine-containing enzyme. Nature 349 438-440. (doi:10.1038/ 349438a0)

Bianco AC, Salvatore D, Gereben B, Berry MJ \& Larsen PR 2002 Biochemistry, cellular and molecular biology, and physiological roles of the iodothyronine selenodeiodinases. Endocrine Reviews 23 38-89. (doi:10.1210/er.23.1.38)

Bonett RM, Hoopfer ED \& Denver RJ 2010 Molecular mechanisms of corticosteroid synergy with thyroid hormone during tadpole metamorphosis. General and Comparative Endocrinology 168 209-219. (doi:10.1016/ j.ygcen.2010.03.014)

Brown DD 2005 Role of deiodinase in amphibian metamorphosis. Thyroid 15 815-821. (doi:10.1089/thy.2005.15.815)

Callebaut I, Curcio-Morelli C, Mornon JP, Gereben B, Buettner C, Huang S, Castro B, Fonseca TL, Harney JW, Larsen PR et al. 2003 The iodothyronine selenodeiodinases are thioredoxin-fold family proteins containing a glycoside hydrolase clan GH-A-like structure. Journal of Biological Chemistry 278 36887-36896. (doi:10.1074/jbc.M305725200)

Campinho MA, Galay-Burgos M, Sweeney GE \& Power DM 2010 Coordination of deiodinase and thyroid hormone receptor expression during the larval to juvenile transition in sea bream (Sparus aurata, Linnaeus). General and Comparative Endocrinology 165 181-194. (doi:10.1016/j.ygcen.2009.06.020)

Cheng Y, Cui Y, Chen HM \& Xie WP 2011 Thyroid disruption effects of environmental level perfluorooctane sulfonates (PFOS) in Xenopus laevis. Ecotoxicology 20 2069-2078. (doi:10.1007/s10646-011-0749-3)

Croteau MC, Davidson M, Duarte-Guterman P, Wade M, Popesku JT, Wiens S, Lean DR \& Trudeau VL 2009 Assessment of thyroid system disruption in Rana pipiens tadpoles chronically exposed to UVB radiation and 4-tert-octylphenol. Aquatic Toxicology 95 81-92. (doi:10.1016/ j.aquatox.2009.05.013)

Curcio-Morelli C, Gereben B, Zavacki AM, Kim BW, Huang S, Harney JW, Larsen PR \& Bianco AC 2003 In vivo dimerization of types 1, 2, and 3 iodothyronine selenodeiodinases. Endocrinology 144 937-946. (doi:10.1210/en.2002-220960)

Darras VM, Verhoelst CHJ, Reyns GE, Kühn ER \& Van der Geyten S 2006 Thyroid hormone deiodination in birds. Thyroid 16 25-35. (doi:10.1089/ thy.2006.16.25)

Dobzhansky T 1973 Nothing in biology makes sense except in the light of evolution. American Biology Teacher 35 125-129.
Duarte-Guterman P \& Trudeau VL 2010 Regulation of thyroid hormone-, oestrogen- and androgen-related genes by triiodothyronine in the brain of Silurana tropicalis. Journal of Neuroendocrinology 22 1023-1031. (doi:10.1111/ j.1365-2826.2010.02047.x)

Eales JG 1997 Iodine metabolism and thyroid-related functions in organisms lacking thyroid follicles: are thyroid also vitamins? Proceedings of the Society for Experimental Biology and Medicine 214 302-317. (doi:10.3181/00379727214-44098)

Egloff C, Crump D, Chiu S, Manning G, McLaren KK, Cassone CG, Letcher RJ, Gauthier LT \& Kennedy SW 2011 In vitro and in ovo effects of four brominated flame retardants on toxicity and hepatic mRNA expression in chicken embryos. Toxicology Letters 207 25-33. (doi:10.1016/j.toxlet.2011.08.015)

Elnagar SA, Scheideler SE \& Beck MM 2010 Reproductive hormones, hepatic deiodinase messenger ribonucleic acid, and vasoactive intestinal polypeptide-immunoreactive cells in hypothalamus in the heat stressinduced or chemically induced hypothyroid laying hen. Poultry Science $\mathbf{8 9}$ 2001-2009. (doi:10.3382/ps.2010-00728)

Fagegaltier D, Lescure A, Walczak R, Carbon P \& Krol A 2000 Structural analysis of new local features in SECIS RNA hairpins. Nucleic Acids Research 15 2679-2689. (doi:10.1093/nar/28.14.2679)

Finnson KW, McLeese JM \& Eales JG 1999 Deiodination and deconjugation of thyroid hormone conjugates and type I deiodination in liver of rainbow trout, Oncorhynchus mykiss. General and Comparative Endocrinology 115 387-397. (doi:10.1006/gcen.1999.7326)

Galton VA, Schneider MJ, Clark AS \& St Germain DL 2009 Life without thyroxine to $3,5,3^{\prime}$-triiodothyronine conversion: studies in mice devoid of the 5'-deiodinases. Endocrinology 150 2957-2963. (doi:10.1210/ en.2008-1572)

García-GC, Jeziorski MC, Valverde-RC \& Orozco A 2004 Effects of iodothyronines on the hepatic thyroid hormone activating pathway in killifish. General and Comparative Endocrinology 135 201-209. (doi:10.1016/ j.ygcen.2003.09.010)

García GC, López-Bojorquez L, Nuñez J, Valverde RC \& Orozco A 2007 3,5-Diiodothyronine in vivo maintains euthyroidal expression of type 2 iodothyronine deiodinase, growth hormone, and thyroid hormone receptor beta1 in the killifish. American Journal of Physiology. Regulatory and Integral Comparative Physiology 29 R877-R883. (doi:10.1152/ajpregu. 00101.2007)

Gereben B, Bartha T, Tu HM, Harney JW, Rudas P \& Larsen PR 1999 Cloning and expression of the chicken type 2 iodothyronine $5^{\prime}$-deiodinase. Journal of Biological Chemistry 274 13768-13776. (doi:10.1074/jbc.274.20. 13768)

Gereben B, Salvatore D, Harney JW, Tu HM \& Larsen PR 2001 The human, but not rat, dio2 gene is stimulated by thyroid transcription factor-1 (TTF-1). Molecular Endocrinology 15 112-124. (doi:10.1210/me.15.1.112)

Gereben B, Zavacki AM, Ribich S, Kim BW, Huang SA, Simonides WS, Zeöld A \& Bianco AC 2008 Cellular and molecular basis of deiodinaseregulated thyroid hormone signaling. Endocrine Reviews 29 898-938. (doi:10.1210/er.2008-0019)

Guadaño-Ferraz A, Obregon MJ, St Germain D \& Bernal J 1997 The type 2 iodothyronine deiodinase is expressed primarily in glial cells in the neonatal rat brain. PNAS 94 10391-11036. (doi:10.1073/pnas.94.19.10391)

Hernandez A, Lyon GJ, Schneider MJ \& St Germain DL 1999 Isolation and characterization of the mouse gene for the type 3 iodothyronine deiodinase. Endocrinology 140 124-130. (doi:10.1210/en.140.1.124)

Hernandez A, Fiering S, Martinez E, Galton VA \& St Germain D 2002 The gene locus encoding iodothyronine deiodinase type 3 (Dio3) is imprinted in the fetus and expresses antisense transcripts. Endocrinology 143 4483-4486. (doi:10.1210/en.2002-220800)

Hernandez A, Martinez ME, Fiering S, Galton VA \& St Germain D 2006 Type 3 deiodinase is critical for the maturation and function of the thyroid axis. Journal of Clinical Investigation 116 476-484. (doi:10.1172/JCI26240)

Heyland A, Price DA, Bodnarova-Buganova M \& Moroz LL 2006 Thyroid hormone metabolism and peroxidase function in two non-chordate animals. Journal of Experimental Zoology. Part B, Molecular and Developmental Evolution 306 551-566. (doi:10.1002/jez.b.21113) 
Holland LZ, Albalat R, Azumi K, Benito-Gutiérrez E, Blow MJ, Bronner-Fraser M, Brunet F, Butts T, Candiani S, Dishaw LJ et al. 2008 The amphioxus genome illuminates vertebrate origins and cephalochordate biology. Genome Research 18 1100-1111. (doi:10.1101/gr.073676.107)

Huang SA \& Bianco AC 2008 Reawakened interest in type III iodothyronine deiodinase in critical illness and injury. Nature Clinical Practice. Endocrinology \& Metabolism 4 148-155. (doi:10.1038/ncpendmet0727)

Ikegami K \& Yoshimura T 2012 Circadian clocks and the measurement of daylength in seasonal reproduction. Molecular and Cellular Endocrinology 349 76-81. (doi:10.1016/j.mce.2011.06.040)

Isorna E, Obregon MJ, Calvo RM, Vázquez R, Pendón C, Falcón J \& Muñoz-Cueto JA 2009 Iodothyronine deiodinases and thyroid hormone receptors regulation during flatfish (Solea senegalensis) metamorphosis. Journal of Experimental Zoology. Part B, Molecular and Developmental Evolution 312B 231-246. (doi:10.1002/jez.b.21285)

Itoh K, Watanabe K, Wu X \& Suzuki T 2010 Three members of the iodothyronine deiodinase family, dio1, dio2 and dio3, are expressed in spatially and temporally specific patterns during metamorphosis of the flounder, Paralichthys olivaceus. Zoological Science 27 574-580. (doi:10.2108/ zsj.27.574)

Johnson KM \& Lema SC 2011 Tissue-specific thyroid hormone regulation of gene transcripts encoding iodothyronine deiodinases and thyroid hormone receptors in striped parrotfish (Scarus iseri). General and Comparative Endocrinology 172 505-517. (doi:10.1016/j.ygcen.2011.04.022)

Kalsbeek A, Buijs RM, van Schaik R, Kaptein E, Visser TJ, Doulabi BZ \& Fliers E 2005 Daily variations in type II iodothyronine deiodinase activity in the rat brain as controlled by the biological clock. Endocrinology 146 1418-1427. (doi:10.1210/en.2004-0763)

Klaren PH, Haasdijk R, Metz JR, Nitsch LM, Darras VM, Van der Geyten S \& Flik G 2005 Characterization of an iodothyronine 5'-deiodinase in gilthead seabream (Sparus auratus) that is inhibited by dithiothreitol. Endocrinology 146 5621-5630. (doi:10.1210/en.2005-0050)

Klootwijk W, Friesema ECH \& Visser TJ 2011 A nonselenoprotein from amphioxus deiodinates triac but not $\mathrm{T}_{3}$ : is triac the primordial bioactive thyroid hormone? Endocrinology 152 3259-3267. (doi:10.1210/ en.2010-1408)

Kluge B, Renault N \& Rohr KB 2005 Anatomical and molecular reinvestigation of lamprey endostyle development provides new insight into thyroid gland evolution. Development Genes and Evolution 215 32-40. (doi:10.1007/s00427-004-0450-0)

Kuiper GG, Klootwijk W, Morvan Dubois G, Destree O, Darras VM, Van der Geyten S, Demeneix B \& Visser TJ 2006 Characterization of recombinant Xenopus laevis type I iodothyronine deiodinase: substitution of a proline residue in the catalytic center by serine (Pro132Ser) restores sensitivity to 6-propyl-2-thiouracil. Endocrinology 147 3519-3529. (doi:10.1210/en.2005-0711)

Langlois VS, Duarte-Guterman P \& Trudeau VL 2011 Expression profiles of reproduction- and thyroid hormone-related transcripts in the brains of chemically-induced intersex frogs. Sexual Development: Genetics, Molecular Biology, Evolution, Endocrinology, Embryology, and Pathology of Sex Determination and Differentiation 5 26-32. (doi:10.1159/000322875)

Laudet V 2011 The origins and evolution of vertebrate metamorphosis. Current Biology 21 R726-R737. (doi:10.1016/j.cub.2011.07.030)

Leonard JL, Simpson G \& Leonard DM 2005 Characterization of the protein dimerization domain responsible for assembly of functional selenodeiodinases. Journal of Biological Chemistry 280 11093-11100. (doi:10.1074/ jbc.M500011200)

Li W, Zha J, Li Z, Yang L \& Wang Z 2009 Effects of exposure to acetochlor on the expression of thyroid hormone related genes in larval and adult rare minnow (Gobiocypris rarus). Aquatic Toxicology 31 87-93. (doi:10.1016/ j.aquatox.2009.06.002)

Li W, Zha J, Yang L, Li Z \& Wang Z 2011 a Regulation of thyroid hormone related genes mRNA expression by exogenous $T_{3}$ in larvae and adult Chinese rare minnow (Gobiocypris rarus). Environmental Toxicology and Pharmacology 31 189-197. (doi:10.1016/j.etap.2010.10.007)

Li R, Hu Y, Ni Y, Xia D, Grossmann R \& Zhao R $2011 b$ Leptin stimulates hepatic activation of thyroid hormones and promotes early posthatch growth in the chicken. Comparative Biochemistry and Physiology. Part A, Molecular \& Integrative Physiology 160 200-206. (doi:10.1016/j.cbpa. 2011.06.001)

Lorenz C, Opitz R, Lutz I \& Kloas W 2009 Corticosteroids disrupt amphibian metamorphosis by complex modes of action including increased prolactin expression. Comparative Biochemistry and Physiology. Toxicology \& Pharmacology 150 14-21. (doi:10.1016/j.cbpc.2009.05.013)

Lu J \& Holmgren A 2009 Selenoproteins. Journal of Biological Chemistry 284 723-727. (doi:10.1074/jbc.R800045200)

Luna M, Guzmán G, Navarro L, de la Peña SS \& Valverde-R C 1995 Circadian rhythm of type II $5^{\prime}$ deiodinase activity in the rat hypothalamicpituitary-adrenal axis. Endocrine 8 597-601. (doi:10.1007/BF02953025)

Marlatt VL, Gerrie E, Wiens S, Jackson F, Moon TW \& Trudeau VL 2012 Estradiol and triiodothyronine differentially modulate reproductive and thyroidal genes in male goldfish. Fish Physiology and Biochemistry 38 283-296. (doi:10.1007/s10695-011-9506-z)

Martínez LM, Orozco A, Villalobos P \& Valverde-R C 2008 Cloning and characterization of a type 3 iodothyronine deiodinase (D3) in the liver of the chondrichtyan Chiloscyllium punctatum. General and Comparative Endocrinology 156 464-469. (doi:10.1016/j.ygcen.2008.02.012)

Mebis L \& Van den Berghe G 2009 The hypothalamus-pituitary thyroid axis in critical illness. Netherlands Journal of Medicine 67 332-340.

Mohácsik P, Zeöld A, Bianco AC \& Gereben B 2011 Thyroid hormone and the neuroglia: both source and target. Journal of Thyroid Research 2011215718.

Morvan Dubois G, Sebillot A, Kuiper GG, Verhoelst CH, Darras VM, Visser TJ \& Demeneix BA 2006 Deiodinase activity is present in Xenopus laevis during early embryogenesis. Endocrinology 147 4941-4949. (doi:10.1210/en.2006-0609)

Ng L, Goodyear RJ, Woods CA, Schneider MJ, Diamond E, Richardson GP, Kelley MW, St Germain DL, Galton VA \& Forrest D 2004 Hearing loss and retarded cochlear development in mice lacking type 2 iodothyronine deiodinase. PNAS 101 3474-3479. (doi:10.1073/pnas.0307402101)

Nobel S, Abrahmsen L \& Opperman U 2001 Metabolic conversion as a prereceptor control machanism for lipophilic hormones. European Journal of Biochemistry 268 4113-4125. (doi:10.1046/j.1432-1327.2001.02359.x)

Noyes PD, Hinton DE \& Stapleton HM 2011 Accumulation and debromination of decabromodiphenyl ether (BDE-209) in juvenile fathead minnows (Pimephales promelas) induces thyroid disruption and liver alterations. Toxicological Sciences 122 265-274. (doi:10.1093/toxsci/kfr105)

Orozco A \& Valverde-R C 2005 Thyroid hormone deiodination in fish (review). Thyroid 15 799-813. (doi:10.1089/thy.2005.15.799)

Orozco A, Silva JE \& Valverde-R C 1997 Rainbow trout liver expresses two iodothyronine phenolic deiodinase pathways with the characteristics of mammalian types I and II 5'deiodinases. Endocrinology 138 254-258. (doi:10.1210/en.138.1.254)

Orozco A, Linser PJ \& Valverde-R C 2000 Kinetic characterization of outerring deiodinase activity (ORD) in the liver, gill and retina of Fundulus heteroclitus. Comparative Biochemistry and Physiology. Part B, Biochemistry \& Molecular Biology 126 283-290. (doi:10.1016/S0305-0491(00)00186-3)

Orozco A, Jeziorski MC, Linser PJ, Greenberg RM \& Valverde-R C 2002 Cloning of the gene and complete cDNA encoding a type 2 deiodinase in Fundulus heteroclitus. General and Comparative Endocrinology 128 162-167. (doi:10.1016/S0016-6480(02)00071-0)

Orozco A, Villalobos P, Jeziorski MC \& Valverde-R C 2003 The liver of Fundulus heteroclitus expresses deiodinase type $1 \mathrm{mRNA}$. General and Comparative Endocrinology 130 84-91. (doi:10.1016/S0016-6480(02)00570-1)

Palioura S, Sherrer RL, Steitz TA, Söll D \& Simonovic M 2009 The human SepSecS-tRNASec complex reveals the mechanism of selenocysteine formation. Science 325 321-325. (doi:10.1126/science.1173755)

Paris M, Brunet F, Markov GV, Schubert M \& Laudet V 2008 The amphioxus genome enlightens the evolution of the thyroid hormone signaling pathway. Development Genes and Evolution 218 667-680. (doi:10.1007/ s00427-008-0255-7)

Paris M, Hillenweck A, Bertrand S, Delous G, Escriva H, Salko D, Cravedi J-P \& Laudet V 2010 Active metabolism of thyroid hormone during metamorphosis in amphioxus. Integrative and Comparative Biology 50 63-74. (doi:10.1093/icb/icq052) 
Picard-Aitken M, Fournier H, Pariseau R, Marcogliese DJ \& Cyr DG 2007 Thyroid disruption in walleye (Sander vitreus) exposed to environmental contaminants: cloning and use of iodothyronine deiodinases as molecular biomarkers. Aquatic Toxicology 83 200-211. (doi:10.1016/j.aquatox. 2007.04.004)

Revel FG, Saboureau M, Pévet P, Mikkelsen JD \& Simonneaux V 2006 Melatonin regulates type 2 deiodinase gene expression in the Syrian hamster. Endocrinology 147 4680-4687. (doi:10.1210/en.2006-0606)

Rodríguez EM, Blázquez JL \& Guerra M 2010 The design of barriers in the hypothalamus allows the median eminence and the arcuate nucleus to enjoy private milieus: the former opens to the portal blood and the latter to the cerebrospinal fluid. Peptides 31 757-776. (doi:10.1016/j.peptides. 2010.01.003)

Sagar GD, Gereben B, Callebaut I, Mornon JP, Zeöld A, Curcio-Morelli C, Harney JW, Luongo C, Mulcahey MA, Larsen PR et al. 2008 The thyroid hormone-inactivating deiodinase functions as a homodimer. Molecular Endocrinology 22 1382-1393. (doi:10.1210/me.2007-0490)

Sanders JP, van der Geyten S, Kaptein E, Darras VM, Kühn ER, Leonard JL \& Visser TJ 1997 Characterization of a propilthiouracil-insensitive type I iodothyronine deiodinase. Endocrinology 138 5153-5160. (doi:10.1210/ en.138.12.5153)

Schneider MJ, Fiering SN, Pallud SE, Parlow AF, St Germain DL \& Galton VA 2001 Targeted disruption of the type 2 selenodeiodinase gene (DIO2) results in a phenotype of pituitary resistance to $\mathrm{T}_{4}$. Molecular Endocrinology 15 2137-2148. (doi:10.1210/me.15.12.2137)

Schneider M, Fiering S, Thai B, Wu SY, St Germain E, Parlow AF, St Germain D \& Galton A 2006 Targeted disruption of the type 1 selenodeiodinase gene (Dio1) results in marked changes in thyroid hormone economy in mice. Endocrinology 147 580-589. (doi:10.1210/ en.2005-0739)

Shepherdley CA, Daniels CB, Orgeig S, Richardson SJ, Evans BK \& Darras VM 2002a Glucocorticoids, thyroid hormones, and iodothyronine deiodinases in embryonic saltwater crocodiles. American Journal of Physiology. Regulatory, Integrative and Comparative Physiology 283 R1155-R1163. (doi:10.1152/ajpregu.00015.2002)

Shepherdley CA, Richardson SJ, Evans BK, Kühn ER \& Darras VM $2002 b$ Thyroid hormone deiodinases during embryonic development of the saltwater crocodile (Crocodylus porosus). General and Comparative Endocrinology 126 153-164. (doi:10.1006/gcen.2002.7786)

Shepherdley CA, Klootwijk W, Makabe KW, Visser TJ \& Kuiper GG 2004 An ascidian homolog of vertebrate iodothyronine deiodinases. Endocrinology 145 1268. (doi:10.1210/en.2003-1248)

Solís-S JC, Orozco A, García-G C, Robles-Osorio L \& Valverde-R C 2011 Bioactivity of thyroid hormones. Clinical significance of membrane transporters, deiodinases and nuclear receptors. Revista de Investigación Clínica 63 287-308.

St Germain D \& Galton VA 1997 The deiodinase family of selenoproteins. Thyroid 7 655-668. (doi:10.1089/thy.1997.7.655)

St Germain DL, Galton VA \& Hernandez A 2009 Minireview: defining the roles of the iodothyronine deiodinases: current concepts and challenges. Endocrinology 150 1097-1107. (doi:10.1210/en.2008-1588)

Tata JR 2006 Amphibian metamorphosis as a model for the developmental actions of thyroid hormone. Molecular and Cellular Endocrinology 246 10-20. (doi:10.1016/j.mce.2005.11.024)

Toyoda N, Zavacki AM, Maia AL, Harney JW \& Larsen PR 1995 A novel retinoid $\mathrm{X}$ receptor-independent thyroid hormone response element is present in the human type 1 deiodinase gene. Molecular and Cellular Biology 15 5100-5112.
Valverde-R C, Orozco A, Becerra A, Jeziorski MC, Villalobos P \& Solis-S JC 2004 Halometabolites and cellular dehalogenase systems. An evolutionary perspective. International Reviews of Cytology 234 143-199. (doi:10.1016/ S0074-7696(04)34004-0)

Villalobos P, Orozco A \& Valverde-R C 2010 Molecular cloning and characterization of a type 3 iodothyronine deiodinase in the pine snake Pituophis deppei. General and Comparative Endocrinology 169 167-173. (doi:10.1016/j.ygcen.2010.08.001)

Walpita CN, Grommen SV, Darras VM \& Van der Geyten S 2007 The influence of stress on thyroid hormone production and peripheral deiodination in the Nile tilapia (Oreochromis niloticus). General and Comparative Endocrinology 150 18-25. (doi:10.1016/j.ygcen.2006.07.002)

Walpita CN, Crawford AD \& Darras VM 2010 Combined antisense knockdown of type 1 and type 2 iodothyronine deiodinases disrupts embryonic development in zebrafish (Danio rerio). General and Comparative Endocrinology 166 134-141. (doi:10.1016/j.ygcen.2009.09.011)

Wambiji N, Park YJ, Kim SJ, Hur SP, Takeuchi Y \& Takemura A 2011 Expression of type II iodothyronine deiodinase gene in the brain of a tropical spinefoot, Siganus guttatus. Comparative Biochemistry and Physiology. Part A, Molecular \& Integrative Physiology 160 447-452. (doi:10.1016/j.cbpa. 2011.03.023)

Warner MH \& Beckett GJ 2010 Mechanisms behind the nonthyroidal illness syndrome: an update. Journal of Endocrinology 205 1-13. (doi:10.1677/JOE09-0412)

Watanabe T, Yamamura T, Watanabe M, Yasuo S, Nakao N, Dawson A, Ebihara S \& Yoshimura T 2007 Hypothalamic expression of thyroid hormone-activating and -inactivating enzyme genes in relation to photorefractoriness in birds and mammals. American Journal of Physiology. Regulatory, Integrative and Comparative Physiology 292 R 568-R572. (doi:10.1152/ajpregu.00521.2006)

Williams GR \& Duncan Bassett JH 2011 Deiodinases: the balance of thyroid hormone. Local control of thyroid hormone action: role of type 2 deiodinase. Journal of Endocrinology 209 261-272. (doi:10.1530/ JOE-10-0448)

Wu T, Shi X, Zhou Z, Wang L, Wang M, Wang L, Huang M, Yang C \& Song L 2012 An iodothyronine deiodinase from Chlamys farreri and its induced mRNA expression after LPS stimulation. Fish $\mathcal{E}$ Shellfish Immunology 33 286-293. (doi:10.1016/j.fsi.2012.05.011)

Yasuo S \& Yoshisura T 2009 Comparative analysis of the molecular basis of photoperiodic signal transduction in vertebrates. Integrative and Comparative Biology 49 507-518. (doi:10.1093/icb/icp011)

Yasuo S, Yoshimura T, Ebihara S \& Korf HW 2007 Temporal dynamics of type 2 deiodinase expression after melatonin injections in Syrian hamsters. Endocrinology 148 4385-4392. (doi:10.1210/en.2007-0497)

Yoshimura T, Yasuo S, Watanabe M, Iigo M, Yamamura T, Hirunagi K \& Ebihara S 2003 Light-induced hormone conversion of $\mathrm{T}_{4}$ to $\mathrm{T}_{3}$ regulates photoperiodic response of gonads in birds. Nature $\mathbf{4 2 6} 178-181$. (doi:10.1038/nature02117)

Yun A, Lee PY, Bazar KA, Daniel SM \& Doux JD 2005 The incorporation of iodine in thyroid hormone may stem from its role as a prehistoric signal of ecologic opportunity: an evolutionary perspective and implications for modern diseases. Medical Hypotheses 65 804-810. (doi:10.1016/j.mehy. 2005.02.007)

Received in final form 27 July 2012

Accepted 3 August 2012

Made available online as an Accepted Preprint 7 August 2012 